University of Louisville

ThinkIR: The University of Louisville's Institutional Repository

Electronic Theses and Dissertations

8-2015

\title{
Cancer caregiving : an exploration of values, burden, repetitive thinking, and depression.
}

Amanda M. Mitchell

University of Louisville

Follow this and additional works at: https://ir.library.louisville.edu/etd

Part of the Counseling Commons

\section{Recommended Citation}

Mitchell, Amanda M., "Cancer caregiving : an exploration of values, burden, repetitive thinking, and depression." (2015). Electronic Theses and Dissertations. Paper 2234.

https://doi.org/10.18297/etd/2234

This Doctoral Dissertation is brought to you for free and open access by ThinkIR: The University of Louisville's Institutional Repository. It has been accepted for inclusion in Electronic Theses and Dissertations by an authorized administrator of ThinkIR: The University of Louisville's Institutional Repository. This title appears here courtesy of the author, who has retained all other copyrights. For more information, please contact thinkir@louisville.edu. 


\title{
CANCER CAREGIVING: AN EXPLORATION OF VALUES, BURDEN, REPETITIVE THINKING, AND DEPRESSION
}

\author{
By \\ Amanda M Mitchell \\ B.S. Grand Valley State University, 2010 \\ M.Ed. University of Louisville, 2013
}

\begin{abstract}
A Dissertation Submitted to the Faculty of the College of Education and Human Development of the University of Louisville in Partial Fulfillment of the Requirements for the Degree of
\end{abstract}

Doctor of Philosophy in Counseling and Personnel Services

\author{
Department of Counseling Psychology \\ University of Louisville \\ Louisville, Kentucky
}

August 2015 



\title{
CANCER CAREGIVING: AN EXPLORATION OF VALUES, BURDEN,
} REPETITIVE THINKING, AND DEPRESSION

\author{
By
}

Amanda M Mitchell

B.S. Grand Valley State University, 2010

M.Ed. University of Louisville, 2013

A Dissertation Approved on

May 4, 2015

by the following Dissertation Committee:

Dissertation Chair

Patrick Pössel, Dr. rer. soc.

Committee Member

Jesse Owen, Ph.D.

Committee Member

Jill Adelson, Ph.D.

Committee Member

Karen Kayser, Ph.D. 


\section{DEDICATION}

This dissertation is dedicated to informal caregivers, many of whom provide countless hours of emotional, social, and physical support to people in their lives. 


\section{ACKNOWLEDGEMENTS}

This dissertation was completed because of the guidance and encouragement of my advisor, Dr. Patrick Pössel. While he would say his support "comes with the job," his dedication to my success at each step of the graduate school process has been unwavering and ultimately shaped both my personal and professional identities. I would also like to thank the committee members for their helpful feedback, which enhanced the quality of this project. Additionally, I want to extend a "thank you" to the centers, hospitals, organizations, and individuals who supported and participated in the study, as well as Caroline Pittard and Sarah Roane for collecting data throughout this project. Finally, I want to acknowledge and express gratitude to my partner, Phil Brown; family, Dean, Karen, and Aaron Mitchell; friends; cohort; and program faculty for their continued support throughout graduate school and the dissertation process. 


\begin{abstract}
CANCER CAREGIVING: AN EXPLORATION OF VALUES, BURDEN, REPETITIVE THINKING, AND DEPRESSION
\end{abstract}

\author{
Amanda M Mitchell
}

May 4, 2015

Individuals who provide emotional, social, and physical care to a care recipient with cancer, without receiving financial compensation, are considered informal cancer caregivers. Research has identified that depression is a significant concern for cancer caregivers and likely impacts the care recipient's health as well. However, limited literature has evaluated constructs that may affect depression in cancer caregivers. The current study explored how intrinsic and extrinsic cultural motivations, caregiver burden, and repetitive thinking relate to depression in a sample of 46 current cancer caregivers. Results revealed that while cancer caregivers did endorse both intrinsic and extrinsic cultural motivations for providing care as well as repetitive thinking, repetitive thinking did not mediate the relationship between cultural motivations and depressive symptoms. However, repetitive thinking did mediate the relationship between caregiver burden and depressive symptoms. Thus, repetitive thinking may play an important role in maintaining and potentially exacerbating caregiving distress. Implications for how the findings may inform caregiver interventions, as well as future research, are discussed. 
TABLE OF CONTENTS

\section{PAGE}

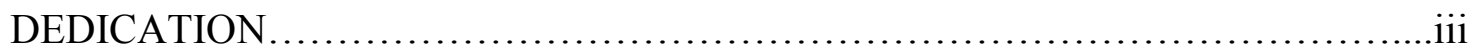

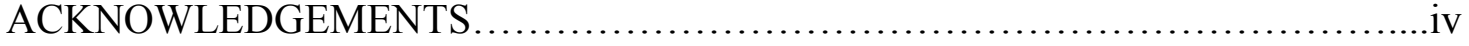

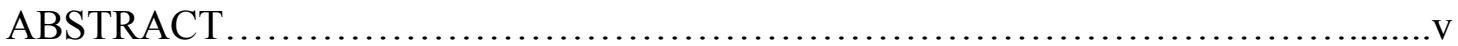

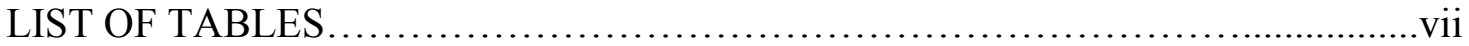

LIST OF FIGURES ....................................................................

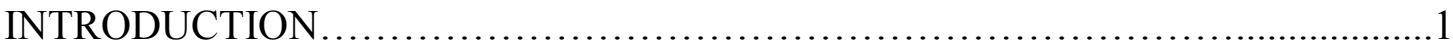

METHODS AND MATERIALS............................................... 11

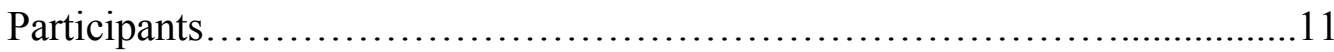

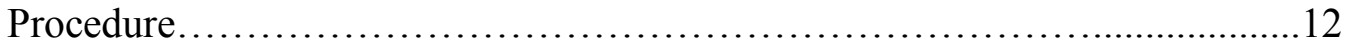

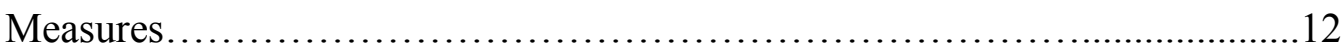

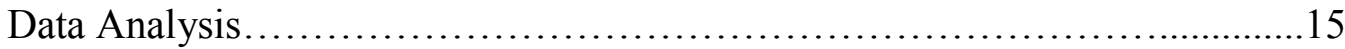

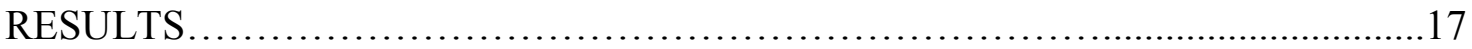

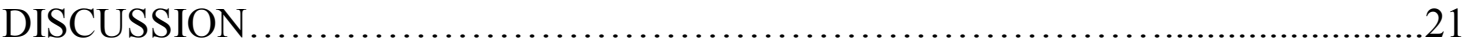

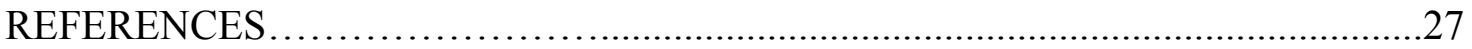

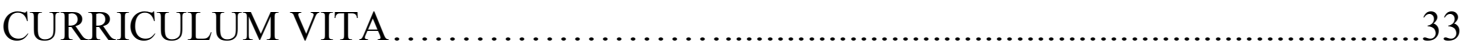




\section{LIST OF TABLES}

PAGE

1 BIVARIATE CORRELATIONS ............................................

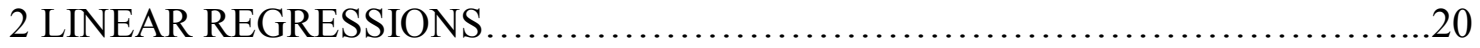




\section{LIST OF FIGURES}

PAGE 1 REPETITIVE THINKING AS A MEDIATOR BETWEEN INTRINSIC (UPPER GRAPH) AND EXTRINSIC CULTURAL MOTIVATIONS (MIDDLE GRAPH) AS WELL AS CAREGIVER BURDEN (LOWER GRAPH) AND DEPRESSIVE SYMPTOMS............................................................. 2 HYPOTHESES RELATED TO INTRINSIC CULTURAL MOTIVATIONS (UPPER GRAPH), EXTRINSIC CULTURAL MOTIVATIONS (MIDDLE GRAPH) AND CAREGIVER BURDEN (LOWER GRAPH) MEDIATION $\ldots \ldots \ldots \ldots \ldots \ldots \ldots \ldots \ldots \ldots 10$ 


\section{CHAPTER I}

\section{CANCER CAREGIVING AND DEPRESSION}

The National Cancer Institute reports that $41 \%$ of Americans will be diagnosed with some type of cancer during their lifetime, based on data collected from 2007 to 2009 (NCI, 2012). The trajectory of the caregiving experience may be specific to the health concerns of the care recipient, thus warranting unique examinations of the experience of cancer caregivers (Clipp \& George, 1993; Kim \& Shulz, 2008). Research has shown that cancer is a significant stressor for families, particularly for people who are responsible for addressing the needs of the individual with cancer without receiving financial compensation, otherwise known as informal caregivers (see Stenberg, Ruland, \& Miaskowski, 2010, for a review). A recent review described depression as the most common studied cancer caregiver outcome, with prevalence rates ranging from $20-73 \%$ (Fletcher, Dodd, Schumacher, \& Miaskowski, 2008). Further, depressive symptoms in cancer caregivers have been associated with greater difficulties related to sleep, anxiety, and fatigue, and lower levels of quality of life and life satisfaction (see Fletcher et al., 2008, for a review). In general, depression is associated with both personal costs to the respective individual, such as negatively affecting quality of life (Wang, Simon, \& Kessler, 2003) and increasing relational distress (Davila, Karney, Hall, \& Bradbury, 2003), and societal costs, including economical (Wang et al., 2003). Additionally, the 
experience of depression likely impacts the caregiver's ability to provide care for the care recipient (Carter \& Chang, 2000). Thus, it seems reasonable that understanding the experience of depression in cancer caregivers will facilitate improved health and wellbeing for the care recipient as well.

Although the body of literature exploring the experience of cancer caregivers has increased exponentially in the past decade, gaps within the literature remain (see Fletcher, Miaskowski, Given, \& Schumacher, 2012, for a review). For example, limited research has studied the role of cultural values or motivations in the experience of cancer caregivers (e.g., Kim, Carver, Deci, \& Kasser, 2008) and no research to date has explored repetitive thinking in cancer caregivers. Given the limited literature base with cancer caregivers, research exploring the experience of other types of caregivers (e.g., dementia caregivers) will be included to help inform our understanding of cancer caregivers. Literature within dementia caregiving suggests that cultural values, caregiver burden, and repetitive thinking may affect caregiver depression (Knight \& Sayegh, 2010). Thus, this particular study will explore the constructs of intrinsic and extrinsic cultural motivations, caregiver burden, and repetitive thinking, and how they affect depression in cancer caregivers.

\section{Cultural Values and Motivations in Caregivers}

The Revised Sociocultural Stress Model posits one version of how cultural values, caregiver burden, coping, social support, and mental and physical health outcomes interact (Knight et al., 2010). The model posits that cultural values indirectly influence caregivers' mental and physical health through two possible pathways: coping and social support. Thus, according to the Revised Sociocultural Stress Model (Knight et 
al., 2010), cultural values, such as familism and filial piety, are expected to indirectly affect caregivers' mental health outcomes through the coping style utilized by the caregiver. Research has explored how familism is associated with broad coping styles (Kim, Knight, \& Flynn Longmire, 2007; Sayegh \& Knight, 2010). Familism is largely understood as the individual's multifaceted identity with the family and may include the strength of dedication, loyalty, and obligation the individual has towards their family (Sayegh et al., 2010). Research has shown that familism is positively associated with the use of maladaptive coping (Kim et al., 2007; Sayegh et al., 2010). For example, Kim and colleagues (2007) found that familism was positively associated with maladaptive coping and not associated with adaptive coping in a sample of African American and Caucasian caregivers. Sayegh et al. (2010) specified two particular types of familism: familial obligations and expected support from the family. Sayegh and colleagues (2010) found that familial obligations was positively associated with maladaptive coping and not associated with adaptive coping, while expected support from the family was not associated with maladaptive or adaptive coping. Filial piety is another cultural value identified in the literature, although it has received limited attention; it has been defined as familial respect and the prioritization of the family's needs over the individual's needs (McCleary \& Blain, 2013). Research conducted by Chun (as cited in Knight et al., 2010) revealed that this particular cultural value may be associated with adaptive coping styles, such as problem-focused coping. Thus, research exploring familism and filial piety has supported a relationship between cultural values and coping. More specifically, research reveals that particular cultural values, such as obligatory familism, may be associated 
with maladaptive coping; whereas other cultural values, such as filial piety, may be related to adaptive coping.

Beyond familism and filial responsibility, other cultural values or motivations have been proposed in the literature. The Cultural Justifications for Caregiving Scale was developed to assess a range of values people may derive from their culture about caregiving, including reciprocity, sense of duty, and religious and spiritual beliefs (Dilworth-Anderson et al., 2004). Romero-Moreno and colleagues (2011) identified that this particular measure assesses both intrinsic and extrinsic cultural motivations. Intrinsic cultural motivations reflect a personal interest and investment as the primary reason to provide care, whereas extrinsic cultural motivations are motives largely driven by obligation and a sense of social pressure. To better understand the relationships between cultural motivations, coping, and distress, Romero-Moreno Márquez-González, Losada, and López (2011) explored how intrinsic and extrinsic cultural motivations for care were associated with rumination and caregivers' mental health outcomes. Results revealed intrinsic cultural motivations for caregiving were negatively associated with engaging in rumination. Further, people that endorsed low intrinsic and high extrinsic cultural motivations for caregiving reported the highest level of rumination, anger, depression, and anxiety compared to people who endorsed other variations in cultural motivations (Romero-Moreno et al., 2011).

To date, only one study has evaluated intrinsic and extrinsic motivations for caring in a sample of cancer caregivers. Kim, Carver, Deci, and Kasser (2008) revealed that for male spousal caregivers, autonomous or more intrinsic-like motivations (e.g., important and meaningful for caregiver to provide care) were associated with less 
depressive symptoms and extrinsic motivations were not significantly associated with depressive symptoms. There was no association between motivations and depressive symptoms with female spousal caregivers. It may be the case that because the extrinsic motivations scale was comprised of only two items with low internal consistency, the findings may have been affected by limited variance and low reliability (Kim et al., 2008). However, it also could be that cultural motivations operate differently for cancer caregivers, as compared to dementia caregivers. Kim et al. (2008) did not include an evaluation of the caregivers' coping skills in the study; thus, more information could be obtained about intrinsic and extrinsic motivations and depressive symptoms with the inclusion of a measure of coping as a mediator, as expected based on theory (Knight et al., 2010) and research (Kim et al., 2007; Losada, Márquez-González, Knight, Yanguas, Sayegh, \& Romero-Moreno, 2010; Sayegh et al., 2010).

\section{Repetitive Thinking in Caregivers}

One particular type of maladaptive coping is repetitive thinking, which is a thought process that requires mental capacity and is characterized by repetition, intrusiveness, and unproductiveness (Ehring, Zetsche, Weidacker, Wahl, Schönfeld, \& Ehlers, 2011). Repetitive thinking is considered a transdiagnostic process (Ehring et al., 2011) and encapsulates other forms of thinking, such as rumination (Nolen-Hoeksema \& Morrow, 1991) and worry (Meyer, Miller, Metzger, \& Borkovec, 1990). A prior research study found that intrinsic cultural motivations were negatively associated with rumination, a disorder-specific type of repetitive thinking, and extrinsic cultural motivations were not associated with rumination (Romero-Moreno et al., 2011). Although Romero-Moreno et al.'s study revealed no relationship between extrinsic 
cultural motivations and rumination, the rumination scale utilized evaluates only the degree to which the individual thinks about their depressive symptoms, including its potential causes and subsequent consequences (Nolen-Hoeksema et al., 1991). Thus, exploring repetitive thinking, which is not limited to one/a disorder-specific content, will capture broader maladaptive thought patterns. One could speculate that a caregiver who endorses intrinsic cultural motivations for caregiving likely receives fulfillment out of the responsibilities associated with such a role and does not brood on the experience, whereas a caregiver endorsing extrinsic cultural motivations for caregiving would be likely to cognitively dwell on the aspects or problems related to caregiving. As such, considering the research, it seems reasonable that intrinsic cultural motivations would be negatively associated with repetitive thinking and extrinsic cultural motivations would be positively associated with repetitive thinking. Research has also shown that repetitive thinking is a vulnerability factor for symptoms of depression and anxiety (Ehring et al., 2011; McEvoy \& Brans, 2013), with experimental studies clearly demonstrating that repetitive thinking is a precursor to changes in mood (Blagden \& Craske, 1996; McLaughlin, Borkovec, \& Sibrava, 2007). Although repetitive thinking has not been explored in cancer caregivers, it seems reasonable that it will have a similar relationship with depressive symptoms in this group as it has in prior research with adults from the general population (Ehring et al., 2011). Thus, engaging in repetitive thinking will facilitate the development of depressive symptoms in cancer caregivers. Finally, as expected according to the Revised Sociocultural Stress Model (Knight et al., 2010), it is hypothesized that repetitive thinking will mediate the relationship between intrinsic and extrinsic cultural motivations and depressive symptoms (see Figure 1, upper and middle graph). 


\section{Caregiver Burden}

Caregiving is taxing and at times it can become burdensome, commonly resulting in a collection of symptoms, such as "loneliness, isolation, fearfulness, and being easily bothered" (Given et al., 2005, p. 3), with expected domains of burden (e.g., impact on schedule) positively associated with depressive symptoms (Given, Given, Stommel, Collins, King, Franklin, 1992). In the Revised Sociocultural Stress Model, caregiver burden operates through coping style to indirectly affect caregivers' mental and physical health (Knight et al., 2010). Research has supported this particular model in dementia caregivers, identifying that cultural values or motivations operate through coping style rather than caregiver burden to affect caregivers' mental health outcomes (Kim et al., 2007; Sayegh et al., 2010). This particular posited interaction between burden, coping, and depressive symptoms has not been explored in cancer caregivers.

Although limited research has examined the coping strategies employed by cancer caregivers (Northfield \& Nebauer, 2010), studies conducted have revealed that caregiver burden is associated with maladaptive coping strategies in cancer caregivers (Papastavrou, Charalambous, \& Tsangari, 2009; Papastavrou, Charalambous, \& Tsangari, 2012). For example, caregivers who were identified as experiencing high burden from the caregiving process endorsed greater use of avoidance and wishful thinking to cope, as compared to more adaptive coping strategies, such as assertiveness (Papastavrou et al., 2012). Negative repetitive thinking has been positively associated with cognitive efforts to control and avoid unwanted thoughts (McEvoy, Moulds, \& Mahoney, 2013). Thus, it seems reasonable that caregivers experiencing burden, including emotional distress (e.g., loneliness), may engage in negative repetitive thinking to cope. In this study, caregiver 
burden is expected to be positively associated with repetitive thinking, especially given the maladaptive nature of repetitive thinking. As expected in the mediation with cultural motivations, repetitive thinking, and depressive symptoms it is hypothesized that repetitive thinking is positively associated with depressive symptoms. Finally, it is expected that repetitive thinking will mediate the relationship between caregiver burden and depressive symptoms (see Figure 1, lower graph).

\section{Hypotheses}

In the current study, the relationships between intrinsic and extrinsic cultural motivations, caregiver burden, repetitive thinking, and caregiver depression will be explored. Specific hypotheses regarding the relationships between constructs were derived from prior research and are depicted in the respective graphs (see Figure 2). 

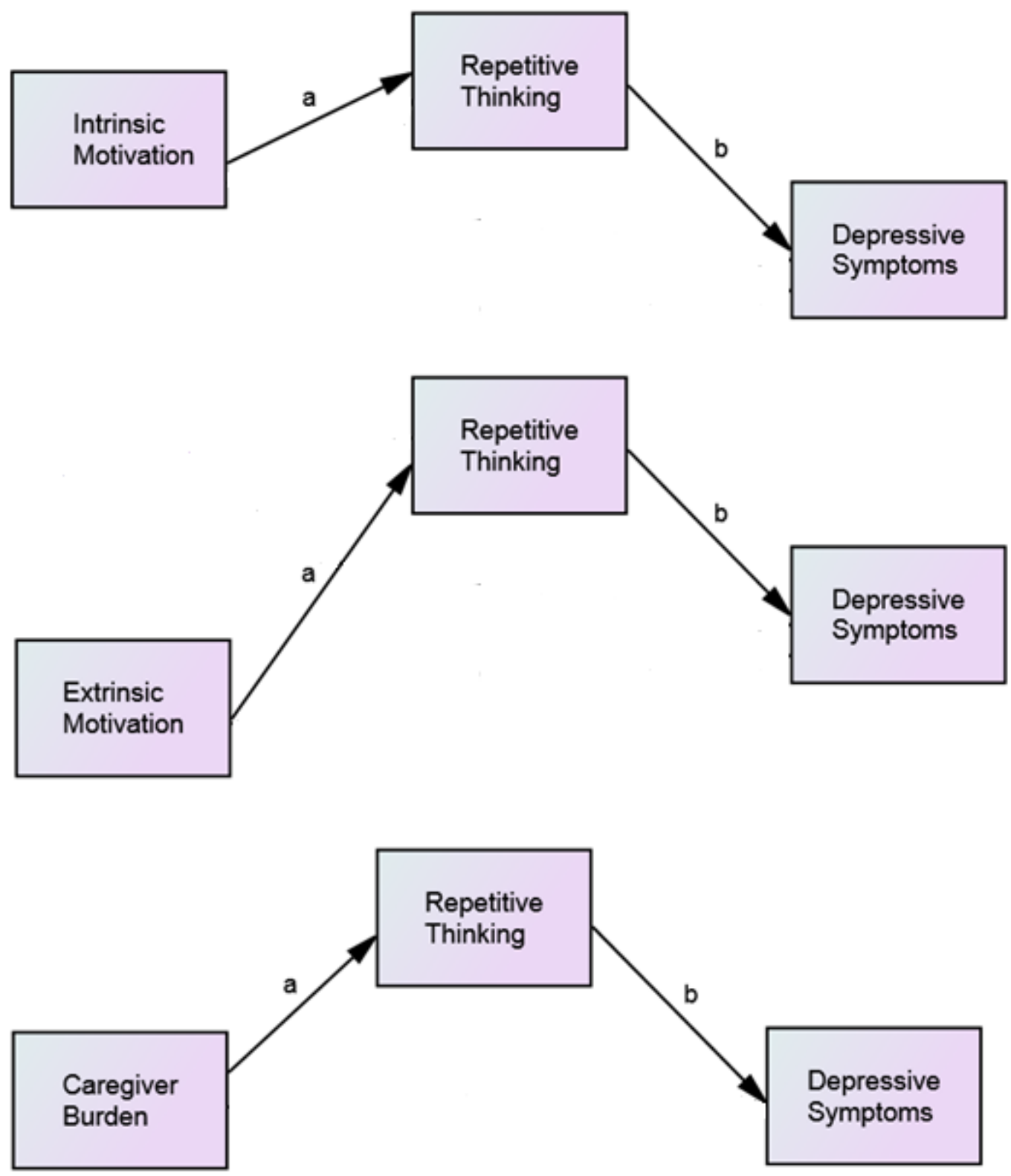

Figure 1

Repetitive Thinking as a Mediator Between Intrinsic (upper graph) and Extrinsic

Cultural Motivations (middle graph) as well as Caregiver Burden (lower graph) and

Depressive Symptoms 

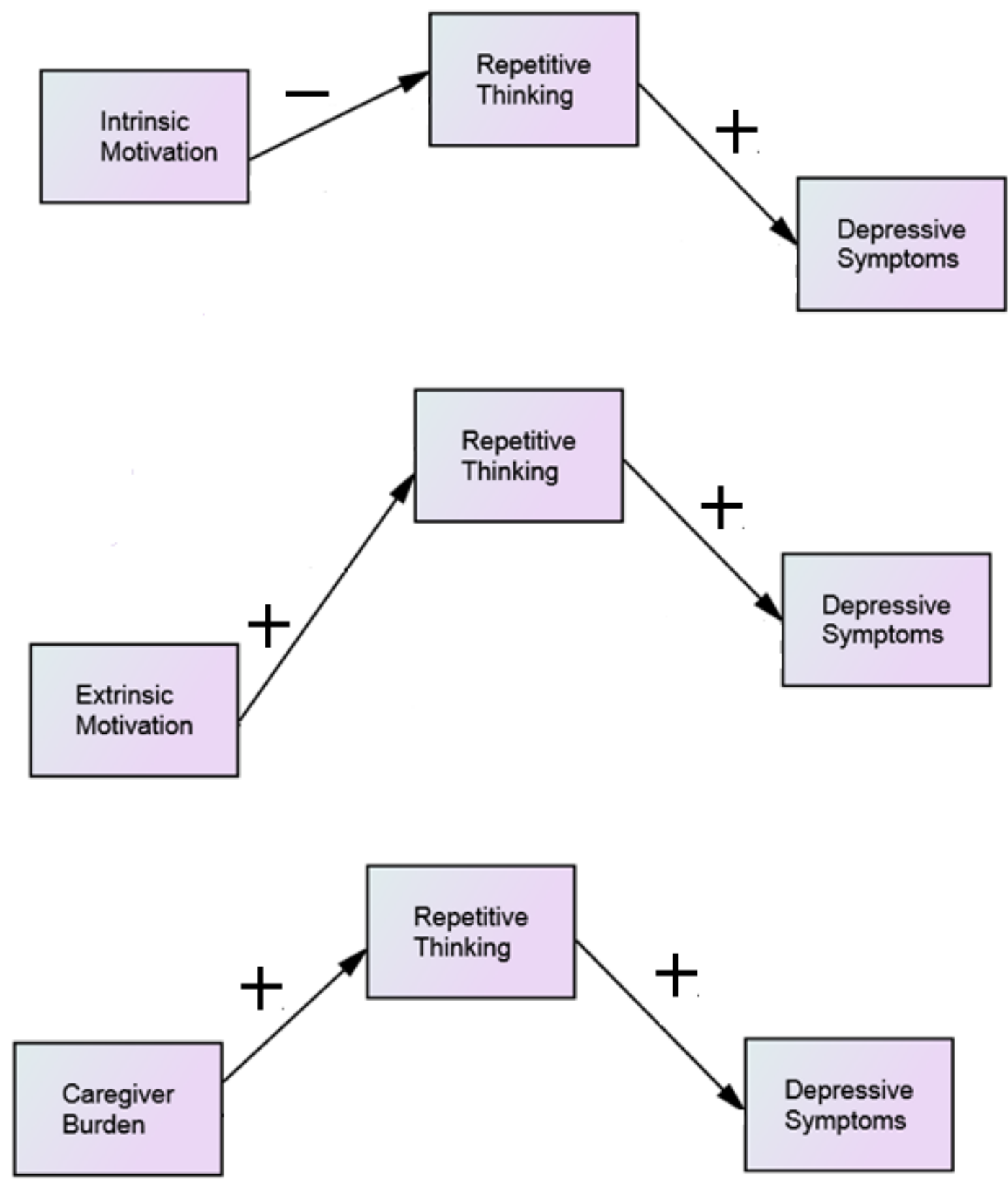

Figure 2

Hypotheses Related to Intrinsic Cultural Motivations (upper graph), Extrinsic Cultural Motivations (middle graph) and Caregiver Burden (lower graph) Mediation 


\section{CHAPTER II}

METHOD

\section{Participants}

Participants consisted of 46 current caregivers of individuals with cancer, with a mean age of 49.28 (SD of 14.18, range of 19 to 77 ). Regarding gender, $67.4 \%$ (31 individuals) of participants identified as female and 32.6\% (15 individuals) identified as male. The racial/ethnic composition of the participants was $87.0 \%$ Caucasian (40 individuals), 8.7\% African American (4 individuals), 2.2\% Asian (1 individual), and $2.2 \%$ mixed race/ethnicity ( 1 individual). Participants were primarily married $(60.9 \%, 28$ individuals), with a high school degree or some college $(54.3 \%, 25$ individuals), and reported an income between $\$ 35,001$ and $\$ 100,000$ (45.6\%, 21 individuals). The relationship of the caregiver to the care recipient included spouses/partners $(50.0 \%, 23$ individuals), child (13.0\%, 6 individuals), parent (15.2\%, 7 individuals), sibling (6.5\%, 3 individuals), friend (4.3\%, 2 individuals), and other (10.9\%, 5 individuals). Caregivers provided care for up to 202 months, with a median of 10.5 months, and the number of hours per week of care ranged from less than one hour to greater than 168 hours within a week, with a median of 30 hours per week. The type of cancer the caregiver identified the care recipient as having included lymphoma/leukemia $(42.2 \%, 19$ individuals), brain 
(11.1\%, 5 individuals), breast (8.9\%, 4 individuals), colorectal (6.7\%, 3 individuals), lung (8.9\%, 4 individuals), and other (e.g., bladder, skin, myeloma; 22.2\%, 10 individuals).

Participants were recruited for this study through in-person requests of individuals on the Bone Marrow Unit of a local hospital (67.4\%, 31 individuals) and in a caregiver support group at a local cancer center (6.5\%, 3 individuals) and email requests to members of Gilda's Club Louisville (21.7\%, 10 individuals) and postings in "UofL Today" on the University of Louisville Belknap campus (4.3\%, 2 individuals),. The study was approved by the Institutional Review Board (IRB) of the University of Louisville.

\section{Procedure}

Participants recruited through emails with members of Gilda's Club Louisville and UofL Today postings were provided information about the study, which included access to an online link to the survey on Qualtrics. Participants recruited in-person were provided information about the study by a research assistant to review. After the participant had reviewed the information, the research assistant returned to identify whether they were interested in participating in the study. The survey consisted of items evaluating cultural motivations for caregiving (Romero-Moreno et al., 2011), caregiver burden (Given et al., 1992), repetitive thinking (Ehring et al., 2011), and depressive symptoms (Radloff, 1977).

\section{Measures}

\section{Cultural Justifications for Caregiving Scale-Revised (CJCS-R; Romero-}

Moreno et al., 2011). To assess cultural motivations for caregiving, participants responded to a revised version of the CJCS. The 11 items comprising the CJCS-R 
evaluate the degree to which caregivers endorse culturally-based reasons or attitudes for caregiving, such as obligation (e.g., I provide care because it is my duty to provide care to dependent family members), role modeling (e.g., I provide care because it is important to set an example for the children in the family), and religious and spiritual beliefs (e.g., I provide care because of my religious and spiritual beliefs). Based on prior research, Romero-Moreno and colleagues (2011) included one additional item to the original 10item scale (Dilworth-Anderson et al., 2004), reflecting the motivation to provide care because there is no alternative option (e.g., I provide care because I have no alternative). Participants responded to the 11 items utilizing a Likert scale ranging from 1 (strongly disagree) to 4 (strongly agree). A factor analysis conducted by Romero-Moreno et al. (2011) revealed a two-factor structure of the CJCS-R: intrinsic cultural values (seven items) and extrinsic cultural values (four items). The items for each factor are summed to produce two respective scores. In this particular study, the word "dependent" was removed from the measure as a descriptor of the caregiving recipient, as this word does not accurately describe a typical individual with cancer as it does with an individual with dementia-related concerns. The overall CJCS-R has shown good internal consistency with a caregiving sample at $\alpha=.90$ and $\alpha=.73$ for intrinsic and extrinsic cultural values, respectively (Romero-Moreno et al., 2011). Cronbach's alphas for this particular study included $\alpha=.86$ for intrinsic cultural values and $\alpha=.68$ for extrinsic cultural values. Additionally, the mean score for intrinsic cultural motivations and extrinsic cultural motivations was $24.21(S D=4.17)$ and $12.48(S D=2.68)$, respectively.

The Caregiver Reaction Assessment (CRA; Given et al., 1992). The CRA was utilized to evaluate caregiver burden in participants (e.g., I have eliminated things from 
my schedule since caring for ). The CRA is comprised of 24 items and participants respond to the items using a Likert scale, ranging from 1 (strongly disagree) to 5 (strongly agree). Items are summed to calculate burden scores in five domains: caregiver esteem, lack of family support, impact on finances, impact on schedule, and impact on health (Given et al., 1992). Although the subscales assess distinct domains, such as finances or schedules, each subscale is tapping into a type of burden the caregiver may be experiencing (Given et al., 1992). Thus, the overall sum score was calculated by summing the subscales up to create an overall burden score. Cronbach's alphas for the burden scale in each domain have ranged from $\alpha=.62$ to $\alpha=.83$ in cancer caregiving samples (Nijboer, Triemstra, Tempelaar, Sanderman, \& van den Bos, 1999). The overall internal consistency for the scale in this particular study is $\alpha=.80$. Additionally, the mean score on the scale was $73.01(S D=10.82)$.

The Perseverative Thinking Questionnaire (PTQ; Ehring et al., 2011). The PTQ was utilized to assess the degree to which participants engage in repetitive thinking. The PTQ is comprised of 15 items (e.g., The same thoughts keep going through my mind again and again), and participants respond to each item utilizing a 5-point Likert scale, ranging from 0 (never) to 4 (almost always). Items are summed to calculate three subscale scores: core characteristics of repetitive negative thinking (i.e., repetitive, intrusive, and difficult to disengage), unproductiveness of repetitive negative thinking, and repetitive negative thinking capturing mental capacity. Further, a total sum score was calculated. The three subscales and total sum score have been shown to exhibit good psychometric properties (Ehring et al., 2011). More specifically, the three subscales exhibited Cronbach's alphas ranging from $\alpha=.77$ to $\alpha=.94$, with Cronbach's alphas for 
the total sum score ranging from $\alpha=.94$ to $\alpha=.95$, in samples of adults (Ehring et al., 2011). The overall internal consistency for the total sum score in this particular study was $\alpha=.94$, and the mean score on the scale was $22.29(S D=10.31)$.

\section{The Center for Epidemiological Studies - Depression Scale (CES—D;}

Radloff, 1977). The CES-D was utilized to assess depressive symptomatology in participants over the past week (e.g., I felt lonely). The scale is comprised of 20 items, and participants respond to each item utilizing a Likert scale ranging from 0 (rarely) to 3 (most of the time). The items are summed to calculate an overall score, with a range from 0 to 60. Prior research has shown a Cronbach's alpha value of $\alpha=.90$ in a caregiving sample (Carter et al., 2000). Cronbach's alpha in this particular study was $\alpha=$ .90 , and the mean score on the scale was $19.08(S D=11.10)$.

\section{Data Analysis}

Four participants did not identify as a current caregiver, and seven participants had missing data on variables evaluated; thus, they were removed prior to analyses. To explore the relationships between variables (Figure 2) and proposed mediation models (Figure 1), the indirect relationship between the predictor and dependent variable through the mediator was examined. To test the proposed mediation model, the widely used approach posited by Preacher and Hayes (2008) was employed. In adhering to this approach, the direct effect between the predictor and dependent variable is not examined. This particular pathway is not considered because in cases characterized by a competitive mediation, in which the indirect effect has significant opposing signs, a direct effect may not be significant when a mediation is present (Zhao, Lynch, \& Chen, 2010). An example of a competitive mediation in this particular study is the indirect effect of 
intrinsic cultural motivations to depressive symptoms through repetitive thinking (Figure 2, upper graph).

Six linear regressions were calculated to examine paths $\mathrm{a}$ and $\mathrm{b}$ in each mediation model (see Figure 1). First, intrinsic cultural motivations served as a predictor and repetitive thinking as a dependent variable. Second, extrinsic cultural motivations served as predictor variable and repetitive thinking as a dependent variable. Third, caregiver burden served as a predictor variable and repetitive thinking as a dependent variable. Fourth, three linear regressions were calculated with repetitive thinking serving as a predictor variable and depressive symptoms as a dependent variable, after controlling for the respective predictor variable in the first three models (i.e., intrinsic cultural motivations, extrinsic cultural motivations, and caregiver burden). Given sample size, the competitive and complementary indirect effects $\left(a^{*} b\right)$ of the mediation models were examined utilizing the RMediation program, as suggested by literature (Tofighi \& MacKinnon, 2011). The RMediatian program provides $95 \%$ confidence intervals for the mediated effect utilizing the distribution of product, Monte Carlo simulations, and an asymptotic normal distribution. The effect is significant when the confidence intervals do not contain zero (Tofighi et al., 2011). 


\section{CHAPTER III}

\section{RESULTS}

Means, standard deviations, and bivariate correlations were calculated with all variables (see Table 1). Repetitive thinking was explored as a mediator in the competitive indirect relationship between intrinsic cultural motivations and depressive symptoms and the complementary indirect relationship between extrinsic cultural motivations and depressive symptoms. Unexpectedly, intrinsic cultural motivations $(\beta=$ $.02, p=.904$; Table 2$)$ and extrinsic cultural motivations $(\beta=.03, p=.840$; Table 2$)$ were not significantly associated with repetitive thinking. As expected, repetitive thinking was positively associated with depressive symptoms after controlling for intrinsic cultural motivations $(\beta=.72, p<.001$; Table 2$)$ and extrinsic cultural motivations $(\beta=.71, p<$ .001 ; Table 2). An examination of the $95 \%$ confidence intervals revealed that the competitive indirect relationship between intrinsic cultural motivations and depressive symptoms $(-0.541,0.615)$ and the complementary indirect relationship between extrinsic cultural motivations and depressive symptoms $(-0.796,0.988)$ both included zero and thus, were insignificant.

Repetitive thinking was also explored as a mediator in the complementary indirect relationship between caregiver burden and depressive symptoms. As predicted, there was a positive association between caregiver burden and repetitive thinking $(\beta=.48, p=.001$; 
Table 2), revealing that the greater burden experienced by the caregiver, the more they engaged in repetitive thinking. Further, there was a positive association between repetitive thinking and depressive symptoms, after controlling for caregiver burden $(\beta=$ $.58, p<.001$; Table 2). An examination of the $95 \%$ confidence interval in the complementary indirect relationship between caregiver burden and depressive symptoms did not contain zero and was therefore significant $(0.113,0.489)$. 
Table 1

Bivariate Correlations

\begin{tabular}{|c|c|c|c|c|c|c|c|c|c|c|c|c|}
\hline Variable & 1 & 2 & 3 & 4 & 5 & 6 & 7 & 8 & 9 & 10 & 11 & 12 \\
\hline 1 Relationship to Care Recipient & -- & & & & & & & & & & & \\
\hline 2 Age & $-.41 * *$ & -- & & & & & & & & & & \\
\hline 3 Ethnicity & -.06 & -.13 & -- & & & & & & & & & \\
\hline 4 Gender & -.11 & -.07 & .57 & -- & & & & & & & & \\
\hline 5 Marital Status & -.09 & .24 & .14 & -.04 & -- & & & & & & & \\
\hline 6 Education Level & -.26 & -.02 & .10 & -.09 & -.17 & -- & & & & & & \\
\hline 7 Income & $-.40 * *$ & $.30 *$ & .07 & .03 & .22 & $.37 *$ & -- & & & & & \\
\hline 8 Intrinsic Motives & .03 & .15 & -.12 & .03 & .01 & -.14 & -.09 & -- & & & & \\
\hline 9 Extrinsic Motives & -.22 & -.07 & -.23 & .12 & -.04 & -.05 & .03 & $.39 * *$ & -- & & & \\
\hline 10 Repetitive Thinking & .19 & -.26 & .00 & -.18 & .16 & .01 & -.15 & .02 & .03 & -- & & \\
\hline 11 Caregiver Burden & -.22 & -.23 & -.05 & -.04 & -.24 & .09 & -.22 & .10 & .28 & $.48^{* *}$ & -- & \\
\hline 12 Depressive Symptoms & .11 & $-.40 * *$ & -.08 & -.04 & -.02 & .01 & $-.30 *$ & -.03 & .21 & $.72 * * *$ & $.57 * * *$ & -- \\
\hline
\end{tabular}

Note. ${ }^{*} p<.05 ; * * p<.01 ; * * * p<.001$ 
Table 2

Linear Regressions

Dependent Variable Repetitive Thinking

\begin{tabular}{|c|c|c|c|c|}
\hline Predictors & $B$ & S.E & $\beta$ & $\overline{R^{2}}$ \\
\hline 1 Intrinsic Motives & .05 & .37 & .02 & .00 \\
\hline 2 Extrinsic Motives & .12 & .58 & .03 & .00 \\
\hline 3 Caregiver Burden & .45 & .13 & $.48 * *$ & .23 \\
\hline Dependent Variable & \multicolumn{4}{|c|}{ Depressive Symptoms } \\
\hline Predictors & $B$ & S.E & $\beta$ & $R^{2}$ \\
\hline 1 Repetitive Thinking ${ }^{\mathrm{a}}$ & .78 & .11 & $.72 * * *$ & .52 \\
\hline 2 Repetitive Thinking ${ }^{\mathrm{b}}$ & .77 & .11 & $.71 * * *$ & .55 \\
\hline 3 Repetitive Thinking ${ }^{\mathrm{c}}$ & .62 & .12 & $.58 * * *$ & .59 \\
\hline
\end{tabular}

Note. ${ }^{a}$ after controlling for intrinsic cultural motivations

${ }^{b}$ after controlling for extrinsic cultural motivations

${ }^{\mathrm{c}}$ after controlling for caregiver burden

$* * p<.01 ; * * * p<.001$ 


\section{CHAPTER IV DISCUSSION}

The purpose of this particular study was to explore intrinsic and extrinsic cultural motivations, caregiver burden, and repetitive thinking, and how they affect depression in cancer caregivers. According to the Revised Sociocultural Stress Model (Knight et al., 2010), cultural motivations and caregiver burden were expected to indirectly influence depressive symptoms through repetitive thinking. As such, it was expected that intrinsic and extrinsic cultural motivations and caregiver burden would be associated with repetitive thinking and repetitive thinking would be associated with depressive symptoms.

Unexpectedly, intrinsic and extrinsic cultural motivations were not associated with repetitive thinking. More specifically, the motives caregivers endorsed for providing care, regardless of whether they were characterized by personal interest or social pressure, were not related to the degree to which they experienced an intrusive thought process about negative caregiving situations. Logically, although repetitive thinking was significantly associated with depressive symptoms, it did not mediate the relationship between intrinsic and extrinsic cultural motivations and depressive symptoms, respectively. In this particular study, caregivers did identify with both 
intrinsic and extrinsic cultural motivations, reporting a higher mean endorsement of motivations compared to a prior study with dementia caregivers (Romero-Moreno et al., 2011). Thus, it appears as though culturally-based reasons and attitudes for caregiving do resonate with cancer caregivers, creating a lens through which they approach the caregiving process. However, the type of cultural motivations did not affect the degree to which caregivers experienced intrusive thoughts about concerns related to caregiving. Further, the correlation between cultural motivations and depressive symptoms revealed no relationship in this particular study; thus, it is reasonable that there was no effect to be mediated.

Prior research has shown that cultural values and motivations have been associated with coping in dementia caregivers, with particular values related to adaptive or maladaptive forms of coping (Kim et al., 2007; Sayegh et al., 2010). Additionally, intrinsic cultural motivations was found to be negatively associated with rumination, a specific type of intrusive thought process and therefore a maladaptive form of coping (Romero-Moreno et al., 2011). Although no research has examined the relationship between cultural motivations and coping in cancer caregivers, Kim and colleagues (2008) revealed that intrinsic motivations and extrinsic motivations were negatively and positively associated with depressive symptoms, respectively, in male, but not female, cancer caregivers. While research has identified similarities among cancer and dementia caregivers, specifically in demographic variables and certain aspects of the caregiving experience (e.g., burden), cancer caregivers typically serve in the caregiver role for a shorter duration of years compared to dementia caregivers (Clipp \& George, 1993; Kim et al., 2008). For example, in one particular study, cancer caregivers provided care for an 
average of 2.2 years, whereas dementia caregivers provided care for an average of 5.6 years (Clipp et al., 1993). Perhaps it is the case that cultural motivations to provide care are related to coping only after the caregiver identifies conflict between cultural motivations and recognizes it as salient to their identity. The extended length of dementia caregiving, compared to cancer caregiving, may provide more opportunities for conflict to exist between motivations in a way that the caregiver perceives as stressful. Another explanation for the unexpected finding might be that appraisal, such as how stressful an individual perceives caregiving, may affect the relationship between cultural motivations and the event of caregiving, as well as how the event of caregiving relates to caregiver coping (Fletcher et al., 2012; Kayser et al., 2013). In other words, although the caregivers in this particular study did appraise the experience of caregiving as burdensome, it may be that because conflict within their cultural motivations to care was not salient for them in that moment, cultural motivations did not influence their coping style.

As expected, caregiver burden was positively associated with repetitive thinking and repetitive thinking was positively associated with depressive symptoms. Further, repetitive thinking mediated the relationship between caregiver burden and depressive symptoms. In other words, the degree to which caregivers experienced an intrusive thought process related to negative caregiving situations is one mechanism through which burden is associated with depressive symptoms in caregivers. This particular finding supports the indirect relationship between caregiver burden and mental health outcomes through coping style, as posited in the Revised Sociocultural Stress Model (Knight et al., 2010). Although there has been limited literature evaluating the coping strategies utilized 
by cancer caregivers (Northfield \& Nebauer, 2010), the positive relationship between caregiver burden and repetitive thinking is consistent with the few articles exploring caregiver burden and maladaptive coping strategies in cancer caregivers (Papastavrou, Charalambous, \& Tsangari, 2009; Papastavrou, Charalambous, \& Tsangari, 2012). Additionally, while no study to date has explored repetitive thinking in cancer caregivers, the positive relationship between repetitive thinking and depressive symptoms is consistent with the broader literature exploring this maladaptive coping strategy in adults (Ehring et al., 2011) and dementia caregivers (Segerstrom, Schipper, \& Greenberg, 2008).

The understanding of repetitive thinking as a mediator in the relationship between caregiver burden and depressive symptoms provides information on how caregiver distress may be maintained and potentially exacerbated during the caregiving process. In other words, heightened cognitive focus on caregiving problems, characterized by repetition, intrusiveness, and unproductiveness (Ehring et al., 2011), is a maladaptive coping process by which distress may manifest as depressive symptoms in cancer caregivers. Based on findings from the current study, it could be that targeting repetitive thinking may be fruitful in interrupting and reducing depressive symptoms in cancer caregivers. For example, research has shown that mindfulness skills are helpful in reducing the degree to which people engage in repetitive thought (Heeren \& Philippot, 2011). Thus, it may be that integrating mindfulness into caregivers' skill sets will address active repetitive thought and ultimately improve caregivers' mood.

The findings from this particular study extend the understanding of the experience of cancer caregivers. First, while cultural motivations may resonate with cancer 
caregivers, they may not play a role in how cancer caregivers cope or whether they experience depressive symptoms. Future research may benefit from exploring whether conflict within cultural motivations or salience of caregiver identity or cultural motivations plays a role in the relationship between cultural motivations and coping style. A limitation of this specific study is the small sample size. Thus, it is possible that the associations between cultural motivation and repetitive thinking are only small and thus, that a larger sample size is necessary to detect these associations. Nevertheless, it is unlikely that a larger sample size would change the results given that no variance is shared between cultural motivations and repetitive thinking, as can be seen in the low coefficients of determination (see Table 2). It is also important to note that the internal consistency for items evaluating extrinsic cultural motivations was lower than the items for intrinsic cultural motivations and only acceptable within this particular sample. Further, it may have been difficult for participants to endorse items reflecting extrinsic cultural motivations (e.g., provide care out of obligation), given the environmental context in which they completed the measures (e.g., care recipients were often in the same building) and the perspective that extrinsic cultural motivations may be perceived as less socially desirable than intrinsic cultural motivations. However, the scale has been utilized in prior research to evaluate extrinsic cultural motivations with a similar internal consistency reported (Romero-Moreno et al., 2011). Second, because repetitive thinking significantly predicts depressive symptoms in cancer caregivers, it may be an important maladaptive coping strategy to examine in continued research, particularly within the context of interventions to support cancer caregivers. Given the limited literature examining coping in cancer caregivers (Northfield et al., 2010), it may be especially 
helpful to continue to explore how coping strategies may mediate the experience of distress and burden with mental and physical health outcomes. Third, this study explored two particular sections or mediations of the Revised Sociocultural Stress Model (Knight et al., 2010), offering support for the role that coping may play in the relationship between burden and mental health outcomes. However, future research would benefit from examining the entire model, including the interplay of the relationships, utilizing a model-level analysis. Additionally, while the mediations in the current study bring a greater depth of understanding to the relationships explored, they were cross-sectional in nature. Thus, future research would benefit from including data collected at three points in time.

Summarized, the current study revealed that while repetitive thinking does not mediate the relationship between cultural motivations and depressive symptoms, it does mediate the relationship between caregiver burden and depressive symptoms in cancer caregivers. The information provided by this study reveals the important and differential role coping may play in the experience of caregiver distress, and future research may benefit from explorations of caregiver distress or burden, coping, and mental and physical health outcomes within the context of cancer caregiver interventions. 


\section{REFERENCES}

Blagden, J. C., \& Craske, M. G. (1996). Effects of active and passive rumination and distraction: A pilot replication with anxious mood. Journal of Anxiety Disorders, $10,243-252$.

Carter, P. A., \& Chang, B. L. (2000). Sleep and depression in cancer caregivers. Cancer Nursing, 23, 410-415.

Clipp, E. C., \& George, L. K. (1993). Dementia and cancer: A comparison of spouse caregivers. The Gerontologist, 33, 534-541.

Davila, J., Karney, B. R., Hall, T. W., \& Bradbury, T. N. (2003). Depressive symptoms and marital satisfaction: Within-subject associations and the moderating effects of gender and neuroticism. Journal of Family Psychology, 17, 557-570.

Dilworth-Anderson, P., Goodwin, P. Y., \& Williams, S. W. (2004). Can culture help explain the physical health effects of caregiving over time among African American caregivers? Journal of Gerontology: Social Sciences, 59, 138-145.

Ehring, T., Zetsche, U., Weidacker, K., Wahl, K., Schönfeld, K., \& Ehlers, A. (2011).

The Perseverative Thinking Questionnaire (PTQ): Validation of a contentindependent measure of repetitive negative thinking. Journal of Behavior Therapy and Experimental Psychiatry, 42, 225-232. 
Fletcher, B. A. S., Dodd, M. J., Schumacher, K. L., \& Miaskowski, C. (2008). Symptom experience of family caregivers of patients with cancer. Oncology Nursing Forum, 35, 23-44.

Fletcher, B. S., Miaskowski, C., Given, B., \& Schumacher, K. (2012). The cancer family caregiving experience: An updated and expanded conceptual model. European Journal of Oncology Nursing, 16, 387-398.

Given, C.W., Given, B., Stommel, M., Collins, C., King, S., \& Franklin, S. (1992). The caregiver reaction assessment (CRA) for caregivers to persons with chronic physical and mental impairments. Research in Nursing and Health, 15, 271-283.

Given, B., Wyatt, G., Given, C., Gift, A., Sherwood, P., DeVoss, D. ... \& Rahbar, M. (2005). Burden and depression among caregivers of patients with cancer at the end-of-life. Oncology Nursing Forum, 31, 1105-1117.

Heeren, A., \& Philippot, P. (2011). Changes in ruminative thinking mediate the clinical benefits of mindfulness: Preliminary findings. Mindfulness, 2, 8-13.

Kayser, K., Cheung, P. K. H., Rao, N., Chan, Y. C. L., Chan, Y., \& Lo, P. H. Y. (2013). The influence of culture on couples coping with breast cancer: A comparative analysis of couples from China, India, and the United States. Journal of Psychosocial Oncology, 32, 264-288.

Kim, Y., Carver, C. S., Deci, E. L., \& Kasser, T. (2008). Adult attachment and psychological well-being in cancer caregivers: The mediational role of spouses' motives for caregiving. Health Psychology, 27, 144-154. 
Kim, J., Knight, B. G., \& Flynn Longmire, C. V. (2007). The role of familism in stress and coping processes among African American and white dementia caregivers: Effects on mental and physical health. Health Psychology, 26, 564-576.

Kim, Y., \& Shulz, R. (2008). Family caregivers' strains: Comparative analysis of cancer caregiving with dementia, diabetes, and frail elderly caregiving. Journal of Aging and Health, 20, 483-503.

Knight, B. G., \& Sayegh, P. (2010). Cultural values and caregiving: The updated sociocultural stress and coping model. Journal of Gerontology: Psychology Sciences, 65, 5-13.

Losada, A., Márquez-González, M., Knight, B. G., Yanguas, J., Sayegh, P., \& RomeroMoreno, R. (2010). Psychosocial factors and caregivers' distress: Effects of familism and dysfunctional thoughts. Aging \& Mental Health, 14, 193-202.

McCleary, L., \& Blain, J. (2013). Cultural values and family caregiving for persons with dementia. Indian Journal of Gerontology, 27, 178-201.

McEvoy, P. M., \& Brans, S. (2013). Common versus unique variance across measures of worry and rumination: Predictive utility and mediational models for anxiety and depression. Cognitive Therapy and Research, 37, 183-196.

McEvoy, P. M., Moulds, M. L., \& Mahoney, A. E. J. (2013). Mechanisms driving preand post-stressor repetitive negative thinking: Metacognitions, cognitive avoidance, and thought control. Journal of Behavior Therapy and Experimental Psychiatry, 44, 84-93. 
McLaughlin, K. A., Borkovec, T. D., \& Sibrava, N. J. (2007). The effects of worry and rumination on affective states and cognitive activity. Behavior Therapy, 38, 2338.

Meyer, T. J., Miller, M. L., Metzger, R. L., \& Borkovec, T. D. (1990). Development and validation of the penn state worry questionnaire. Behaviour Research and Therapy, 28, 225-232.

National Cancer Institute (2012). SEER Stat Fact Sheets: All Sites. Retrieved from http://seer.cancer.gov/statfacts/html/all.html

Nijboer, C., Triemstra, M., Tempelaar, R., Sanderman, R., \& van den Bos, G. A. (1999). Measuring both negative and positive reactions to giving care to cancer patients: Psychometric qualities of the Caregiver Reaction Assessment (CRA). Social Science \& Medicine, 48, 1259-1269.

Nolen-Hoeksema, S., \& Morrow, J. (1991). A prospective study of depression and posttraumatic stress symptoms after a natural disaster: The 1989 loma prieta earthquake. Journal of Personality and Social Psychology, 61, 115-121.

Northfield, S., \& Nebauer, M. (2010). The caregiving journey for family members of relatives with cancer: How do they cope? Clinical Journal of Oncology Nursing, $14,567-577$.

Papastavrou, E., Charalambous, A., \& Tsangari, H. (2009). Exploring the other side of cancer care: The informal caregiver. European Journal of Oncology Nursing, 13, $128-136$. 
Papastavrou, E., Charalambous, A., \& Tsangari, H. (2012). How do informal caregivers of patients with cancer cope: A descriptive study of the coping strategies employed. European Journal of Oncology Nursing, 16, 258-263.

Preacher, K. J., \& Hayes, A. F. (2008). Asymptotic and resampling strategies for assessing and comparing indirect effects in multiple mediator models. Behavior Research Methods, 40, 879-891.

Radloff, L. S. (1977). The CES-D scale: A self-report depression scale for research in the general population. Applied Psychological Measurement, 1, 385-401.

Romero-Moreno, R., Márquez-González, M., Losada, A., \& López, J. (2011). Motives for caring: Relationship to stress and coping dimensions. International Psychogeriatrics, 23, 573-582.

Sayegh, P., \& Knight, B. G. (2010). The effects of familism and cultural justification on the mental and physical health of family caregivers. Journal of Gerontology: Psychological Sciences, 66, 3-14.

Segerstrom, S. C., Schipper, L. J., \& Greenberg, R. N. (2008). Caregiving, repetitive thought, and immune response to vaccination in older adults. Brain, Behavior, and Immunity, 22, 744-752.

Stenberg, U., Ruland, C. M., \& Miaskowski, C. (2010). Review of the literature on the effects of caring for a patient with cancer. Psycho-Oncology, 19, 1013-1025.

Tofighi, D., \& MacKinnon, D. P. (2011). RMeditation: An R package for mediation analysis confidence intervals. Behavior Research Methods, 43, 692-700. 
Wang, P. S., Simon, G. \& Kessler, R. C. (2003). The economic burden of depression and the cost-effectiveness of treatment. International Journal of Methods in Psychiatric Research, 12, 22-33.

Zhao, X., Lynch, J. G., \& Chen, Q. (2010). Reconsidering Baron and Kenny: Myths and truths about mediation analysis. Journal of Consumer Research, 37, 197-206. 


\title{
CURRICULUM VITAE
}

\author{
Amanda M. Mitchell \\ $201 \mathrm{~S} 1460$ E RM 426 \\ Salt Lake City, UT 84112 \\ (989) 513-3204 \\ Mitchell.Amanda.M@gmail.com
}

\section{EDUCATION}

Ph.D. University of Louisville, Louisville, Kentucky

Counseling Psychology (APA-Accredited), Expected August, 2015

Dissertation: Cancer Caregiving: An Exploration of V alues, Burden, Repetitive

Thinking, and Depression

Status: Defended, May 2015

The University of Utah, Salt Lake City, Utah

Pre-Doctoral Intern, University Counseling Center (APA-Accredited)

M.Ed. University of Louisville, Louisville, Kentucky

Counseling Psychology, May, 2013

B.S. Grand Valley State University, Allendale, Michigan

Psychology, Minor in Sociology, May, 2010

\section{PUBLICATIONS}

Mitchell, A.M., Owen, J., Adelson, J., France, T., Inch, L., \& Bergen, C. (in press). The influence of dyadic coping in relationship education for lower income racial/ethnic minority couples. Journal of Family Therapy.

Pössel, P., Mitchell, A. M., Sjögren, E., \& Kristenson, M (in press). Do depressive symptoms mediate the relationship between hopelessness and diurnal cortisol rhythm? International Journal of Behavioral Medicine. 
Pössel, P., Mitchell, A. M., Ronkainen, K., Kaplan, G. A., Kauhanen, J., \& Valtonen, M. (in press). Do depressive symptoms predict the incidence of myocardial infarction independent of hopelessness? Journal of Health Psychology.

Carpenter, B. W., Bukoski, B. E., Berry, M., \& Mitchell, A. M. (in press). Examining the social justice identity of assistant principals in persistently low-achieving schools. Urban Education.

Mitchell, A. M., Pössel, P., Sjögren, E., \& Kristenson M. (2013). Hopelessness the 'active ingredient'? Associations of hopelessness and depressive symptoms with interleukin6. International Journal of Psychiatry in Medicine, 46, 109-117.

Hochbein, C. D., Mitchell, A. M., Pollio, M. (2013). The influence of AYP as an indicator of persistently low-achieving schools. NASSP Bulletin, 97, 270-289.

Mitchell, A. M., \& Pössel, P. (2012). Frontal brain activity pattern predicts depression in adolescent boys. Biological Psychology, 89, 525-527.

Henderson-King, D., \& Mitchell, A. M. (2011). Materialism, intrinsic aspirations, and meaning in life predict students' meanings of education. Social Psychology of Education, 14, 119-134.

\section{Manuscripts Under Review and in Preparation}

Mitchell, A. M., \& Pössel, P. (in preparation). Cancer caregiving: An exploration of values, burden, repetitive thinking, and depression.

Mitchell, A. M., Pössel, P., Van Voorhees, B. W., \& Eaton, W. W. (under review). Associations of depression status and hopelessness with breast cancer: A 24 year follow-up study.

Roane, S., Pössel, P., Mitchell, A. M., Van Voorhees, B. W., \& Eaton, W. W. (under review). The relationship between hopelessness, depressive symptoms, and blood pressure.

Roane, S., Pössel, P., Mitchell, A. M. (under review). Impact of caregiver age and duration of caregiving on caregiver depressive symptoms.

Mitchell, A. M., Henderson-King, D., \& Kielbasa, R. (in preparation). Meanings of education: The role of need for cognition, religiosity, and institutional context.

\section{PROFESSIONAL PRESENTATIONS}

Mitchell, A.M., Owen, J., \& Adelson, J. (2013, June). Family stress model and relationship education: The importance of racial/ethnic minority couples' dyadic coping. Poster presented at the Sixth International Meeting on Stress \& Dyadic Coping, Couples 
Coping with Cancer-Related Stress: Translating Research to Practice, in Louisville, Kentucky.

Mitchell, A. M., \& Pössel, P. (2012, January). Frontal brain activity pattern predicts depression in adolescent boys. Paper presented during Fun Friday Research Colloquium at the University of Louisville, Louisville, Kentucky.

Hochbein, C. D., Mitchell, A., Pollio, M. (2011, November). Gaming the system: AYP as an indicator of persistently low-achieving school performance. Paper presented at the annual University Council for Educational Administration Conference in Pittsburgh, Pennsylvania.

Mitchell, A. M. (2011, March). EEG asymmetry pattern in adolescent boys as risk factor for depression. Paper presented at the annual KPA Foundation Spring Academic Conference in Frankfort, Kentucky.

Hochbein, C., \& Mitchell, A. M. (2010, November). Principal change, accountability, and school achievement. Paper presented at the Brownbag Roundtable Discussion at the University of Louisville, Louisville, Kentucky.

Mitchell, A. M., Kielbasa, R., VanDyke, E., \& Henderson-King, D. (2010, May). Need for cognition and religiosity predict students' meanings of education. Poster presented at the Midwestern Psychological Association Conference, Chicago, Illinois.

Henderson-King, D., \& Mitchell, A. M. (2010, May). Materialism, intrinsic aspirations, and meaning in life predict students' meanings of education. Poster presented at the Midwestern Psychological Association Conference, Chicago, Illinois and Student Scholarship Day at Grand Valley State University, Allendale, Michigan.

Henderson-King, D., Schenk, S., \& Mitchell, A. M. (2009, May). Predicting cosmetic surgery attitudes among college women. Poster presented at the Midwestern Psychological Association Conference, Chicago, Illinois and Student Scholarship Day at Grand Valley State University, Allendale, Michigan.

Mitchell, A. M., \& Vesey, R. (2008, April). Do aspects of the self predict cosmetic surgery attitudes? Poster presented at Student Scholarship Day at Grand Valley State University, Allendale, Michigan.

\section{AWARDS AND GRANTS}

November $2011 \quad$ Travel Grant (\$500), Department of Leadership, Foundations, \& Human Resource Education, University of Louisville

November 2011 Travel Grant $(\$ 100)$, Graduate Student Council, University of Louisville 
May 2010

Psychology Student of the Year (selected by faculty), Grand Valley State University

May 2009

Student Summer Scholars Grant $(\$ 6,000)$, Grand Valley State

University

Faculty Mentor: Dr. Donna Henderson-King

May 2009

Student Academic Conference Fund (\$500), Grand Valley State University

\section{RESEARCH EXPERIENCE}

\section{University of Louisville, Louisville, KY, Graduate Researcher, Mind-Body Research Team}

August 2010 to present

Supervisor: Dr. Patrick Pössel

Develop and collaborate on research projects examining risk factors of depression, depression, and their relationship with physical health. Conducting analyses using quantitative approaches (e.g., cox regressions) and contribute to the analysis process by coding articles for meta-analyses. Discuss findings and implications through manuscript writing and publishing and presentations at state and local conferences.

\section{University of Louisville, Louisville, KY, Graduate Assistantship, Education Research} August 2010 to May 2013

Supervisors: Dr. Craig Hochbein, Dr. Bradley Carpenter, \& Dr. Kristin Wilson

Collaborated on research design and methodology, including organizing and managing large data sets, transcribing interviews, and conducting analyses using quantitative (structural equation modeling and regression discontinuities) and qualitative approaches. Discussed findings and implications through manuscript writing and publishing and presentations at local and national conferences.

\section{Grand Valley State University, Allendale, MI, Undergraduate Researcher, Social Psychology Research}

January 2008 to August 2010

Supervisor: Dr. Donna Henderson-King

Developed and collaborated on research ideas and projects related to students' meanings of education and attitudes about cosmetic surgery. Initiated the process of data collection at a second local university. Organized, managed, and assisted research assistants with the data collection process. Coded, entered, and analyzed data. Discussed findings and implications through manuscript writing and publishing and presentations at local and regional conferences. Applied and received a grant through the university to continue research.

\section{Grand Valley State University, Allendale, MI, Undergraduate Researcher, Interpersonal Violence Research}

August 2009 to August 2010

Supervisor: Dr. Tara Cornelius 
Collaborated on research projects exploring romantic partner violence. Assisted with the data collection process (e.g., conducted interviews) and entered data.

\section{TEACHING EXPERIENCE}

\section{University of Utah, Salt Lake City, UT}

Co-Instructor for Multicultural Issues

August 2014 to December 2014, ED PS 3010, Supervisor: Dr. Karen Cone-Uemura

Content of course introduces students to multicultural concepts, including the role of the cultural environment in understanding self and others.

\section{University of Utah, Salt Lake City, UT}

Guest Facilitator for Strategies for College Success

November 24, 2014, Facilitated Panel on Intersecting Identities

Bellarmine University, Louisville, KY

Guest Lecture for Health Psychology

April 10, 2014, Understanding the Caregiving Experience: Current Research

\section{University of Louisville, Louisville, KY}

Teaching Assistant for Advanced Issues in Research Design

July 2013 to August 2013, ELFH 789, Supervisor: Dr. Craig Hochbein

Content of course spanned quantitative and qualitative research methodology, with a focus on study designs that allow for causal interpretations.

\section{University of Louisville, Louisville, KY}

Teaching Assistant for Intro to Research Methods and Statistics

May 2011 to August 2011, ELFH 600, Supervisor: Craig Hochbein

Content of course consisted of statistical methodology and analyses, including discussions about hypotheses, sampling, correlations, and regressions.

\section{CLINICAL EXPERIENCE}

\section{University of Utah Counseling Center, Salt Lake City, UT, Pre-Doctoral Intern}

August 2014 to present, Supervisors: Dr. Lois Huebner and Dr. Karen Cone-Uemura

Conduct structured intakes and provide individual therapy to clients utilizing empirically-supported approaches, while integrating feedback measures into treatment process. Co-facilitate the Women Owning Womanhood (WOW) therapy group, the Mindful Approach to Work/Life Balance Workshop, and the Sharing and Caring Grief Support Group. Conduct clinical interviews and administer, score, and interpret assessments evaluating client's mental health functioning. Supervise three psychology doctoral students in their clinical work. Co-facilitate and engage in presentations, tabling events, and social media for outreach purposes.

Indiana University Southeast Counseling Center, New Albany, IN, Practicum Intern August 2013 to May 2014, Supervisor: Dr. Michael Day 
Conducted intakes and provided individual therapy utilizing empirically-supported treatments, while integrating feedback measures to inform treatment with clients. Provided consultation with students about graduate school in psychology.

\section{University of Louisville Counseling Center, Louisville, KY, Graduate Assistant Outreach Coordinator}

August 2013 to May 2014, Supervisor: Dr. Kathy Pendleton

Created and maintained social networking site and updated website to connect with student community. Facilitated outreach events focused on reducing stigma associated with seeking mental health care. Developed and facilitated presentations and dialogue about mental health with various student groups (e.g., residential assistants, LGBT Center ambassadors). Collaborated with Office of Health Promotion to facilitate stress resiliency and flash nap workshops with several students groups and organizations. Collaborated with Campus Health Services on the National College Depression Partnership to improve interdisciplinary care services on campus related to depression.

\section{The Brook Hospital - KMI, Louisville, KY, Practicum Intern}

January 2013 to August 2013, Supervisor: Dr. Stelios Stylianou

Conducted structured intakes with clients to evaluate mental health functioning. Obtained collateral information to better inform treatment. Provided individual therapy grounded in empirically-supported approaches. Facilitated and co-facilitated group therapy, specifically a skills group focused on emotion regulation and a psychoeducation group. Actively contributed during a consultation group and treatment team meetings with multidisciplinary practitioners. Incorporated feedback measures to inform treatment.

\section{Weisskopf Child Evaluation Center, Louisville, KY, Practicum Intern}

August 2012 to January 2013, Supervisor: Dr. Eva Markham

Conducted evaluations with interdisciplinary teams to assess children for developmental delays and disabilities. Administered and scored assessments. Provided individual and family therapy with children and caregivers, as well as cotherapy with occupational therapists, utilizing empirically-supported treatments.

\section{Maloney Center, Louisville, KY, Practicum Intern}

May 2012 to August 2012, Supervisor: Dr. Kathleen Kirby

Conducted clinical interviews with clients and caregivers. Conceptualized cases and formulated appropriate assessment batteries. Administered, scored, and interpreted assessments. Facilitated assessment feedback sessions with clients and their caregivers.

\section{University of Louisville Counseling Center, Louisville, KY, Practicum Intern} August 2011 to May 2012, Supervisors: Dr. Terri White and Dr. Joanna Morse

Conducted structured intakes and provided empirically-supported individual therapy with clients. Integrated assessment into treatment with clients. Co-facilitated a Women's Group. Actively contributed during multidisciplinary team meetings. 


\section{PROFESSIONAL SERVICE}

\section{American Psychological Association of Graduate Students (APAGS) Advocacy Coordinating Team (ACT)}

- APAGS-ACT Regional Advocacy Coordinator, Northeast Region, August 2013 to June 2015

- APAGS-ACT State Advocacy Coordinator, Kentucky, August 2012 to August 2013

- APAGS-ACT Campus Representative, University of Louisville, October 2011 to July 2012

\section{Kentucky Psychological Association (KPA)}

- Undergraduate Poster Judge for the Spring Academic Conference, March 2013, 2014

- $\quad$ APAGS Liaison (as defined by KPA) for the KPA Board of Directors, August 2012 to August 2013

- Student Member of KPA Internship Task Force, June 2012 to August 2013

\section{University of Louisville}

- Reviewed Conference Submissions for Spring Research Conference, University of Louisville, Louisville, KY, March 2012

- Student Interviewer for Counseling Psychology Doctoral Program, University of Louisville, Louisville, KY, January 2011

- Student Member of Counseling Psychology Diversity Committee, University of Louisville, Louisville, KY, September 2010 to August 2013

\section{University of Utah}

- Member of Outreach Coalition Committee, August 2014 to July 2015

- Member of Selection Committee for Incoming Pre-Doctoral Interns, August 2014 to February 2015

\section{PROFESSIONAL MEMBERSHIPS}

American Psychological Association (APA) 
Society of Counseling Psychology (Division 17)

Society for the Psychology of Women (Division 35)

Health Psychology (Division 38)

LGBTQ-affirmative Psychotherapist Guild of Utah

Psi Chi Honor Society, Grand Valley State University 